DOi: $10.21554 /$ hrr.042001

\title{
SERBIAN ADAPTATION OF THE PSYCHOLOGICAL MINDEDNESS SCALE - PSYCHOLOGY STUDENTS SAMPLE
}

Original scientific paper

\section{Ivan Anđelković1}

${ }^{1}$ Department of Social Policy and Social Work, Faculty of Philosophy, University of Nis, Republic of Serbia

\begin{abstract}
The purpose of this research was to evaluate the quality criteria and the factor structure of the Serbian translation of the Psychological Mindedness Scale (PMS) (Shill and Lumley, 2002). In this paper we offer the detailed description of the translation and validation procedures we fallowed. Psychological Mindedness outlines the interest as well as the ability of an individual to introspectively reflect on emotions and conflicts. The sample consisted of 166 university students. Results indicate good psychometric propperties. Internal consitancy is good. Explorative factor analysis suggested that a four factor solution is better that the original five factor, because of fewer cross-loadings and better content validity of the factors. Good convergent validity was demonstrated by a strong negative correlation between the whole PMS, and all four factors separately, and Toronto Alexithymia Scale (TAS-20). Perspectives for further improvement of the instrument and its application in therapeutic process are discussed in the conclusion.
\end{abstract}

Keywords: Psychological Mindedness, Self-report measures, Translation, Validation

\footnotetext{
${ }^{1}$ Correspondence to:

Ivan Anđelković Department of Social Policy and Social Work, Faculty of Philosophy, University of Nis, Republic of Serbia Cirila i Metodija 2, 18000 Nis, Republic of Serbia

Email: ivan.andjelkovic@filfak.ni.ac.rs
} 


\section{INTRODUCTION}

Psychological Mindedness (PM) is one of the many concepts developed by psychologists, psychiatrists, or philosophers which in their essence refer to the human ability, and willingness to reflect about oneself. Along with introspection, metallization, or mindfulness, the concept of psychological mindedness represents the unique attitude of a human being to be the subject and the object of his own thinking. The purpose of this paper is to present the concept of Psychological Mindedness, to inform the reader about previous attempts of operationalizing the concept, and to discuss the validation results of the Serbian translation of the Psychological Mindedness Scale (PMS).

\section{DEFINITION AND OPERATIONALIZATION OF THE CONCEPT}

The concept of Psychological Mindedness first appeared in literature in the first half of the twentieth century. Its roots can be found in psychodynamic theory, or more precisely, according to Boylan (2006) in Jung's “introversion", Murray's “intraception", and James' "tendermindedness". Apelbaum (1973) states that, due to its similarity, PM is often used synonymously with the concepts of introspection, self-awareness, insight, and reflection. The same author gave the most influential definition of PM as "a person's ability to see relationships among thoughts, feelings, and actions, with the goal of learning the meanings and causes of his experience and behaviour" (1973, p.36). At least four dimensions can be differentiated in this definition: 1) the ability to find causes and motives that underlie the behaviour; 2 ) the curiosity and interest in the way human mind works, taking both cognitive and emotional part of mental functioning into account; 3) self-directed thinking; 4) the ability to use psychological thinking in the context of psychotherapy.

Later redefining of the concept (Giromini, et al., 2015; Hall, 1992; McCallum \& Piper, 1990) expanded the meaning of Psychological Mindedness.
The dimensions included to the concept refer to 1) the interest in others, not only oneself; 2) understanding the connection between intrapsychic processes and difficulties - symptoms manifested in behaviour; 3) willingness to comprehend and change motivational forces which drive human behaviour.

Authors who do not belong to the psychoanalytic orientation only recently encountered the concept of Psychological Mindedness. Grant (2001) adjusted the definition of PM to the cognitive-behavioural perspective. He sees Psychological Mindedness as a meta-cognition, a predisposition to engage in acts of affective and intellectual inquiry into how and why people behave, think and feel in the way they do.

Finally, we will cite the definition of PM given by the authors of the Psychological Mindedness Scale, which validation on the Serbian sample is the main topic of this paper. Its authors Conte, Ratto, and Karusa (1996), offered a definition from a "transtheoretical" methodology-based perspective. They define PM as "an attribute of an individual that presupposes a degree of access to one's feelings, a willingness to try to understand oneself and others, a belief in the benefit of one's own problems, and interest in the meaning and motivation of one's own and others, thoughts, feelings, behavior and capacity for change," according to Boylan (2006, p. 15).

\section{PSYCHOLOGICAL MINDEDNESS SCALE}

Before we describe the Psychological Mindedness Scale, we would like to mention that this scale is not the only instrument created to measure Psychological Mindedness. Some of the instruments used for this purpose, and cited in literatue include Psychological Mindedness Assesment Procedure (PMAP; McCallum \& Piper, 1990) and Balanced Index of Psychological Mindedness (BIPM; Nyklicek \& Denollet, 2009). The first one operationalizes PM as a participant's understanding of the problem presented by two patients on a video tape. The second is a 14-item self-report scale, which measures the person's interest and ability to be in touch with and reflect on his mental contents. 
There are two reasons why we chose Psychological Mindedness Scale for our study. Firstly, PMS has already been used in a number of studies on different samples (clinical and community), and secondly, there are two other versions of the scale (Bulgarian and German) that are being developed simultaniously, which will give us the opportunity in the near future to compare our results with these studies. The 45 items of the scale are given in the Apendix.

PMS is a 45 -item scale, constructed primarily to measure the aptitude of a patient for psychodynamic psychotherapy (Conte, etal., 1996). Although its authors belong to the psychodynamic background, the scale itself was not constructed so that it operationalizes any psychodynamic variable. On the contrary, it represents an integration of various definitions of Psychological Mindedness (Boylan, 2006).

The authors of the scale (Conte, et al., 1996) conducted a factor analysis (PCA, with varimax rotation) on the sample of 256 psychiatric patients. They chose a fivefactor solution, which explains $38 \%$ of the variance, and includes 27 out of 45 items. They labeled the factors as follows:

I. Willingness to try to understand oneself and others (10 items)

II. Openness to new ideas and capacity for change (5 items)

III. Access to one's feelings (5 items)

IV. Belief in the benefits of discussing one's problems (3 items)

$\mathrm{V}$. Interest in meaning and motivation of own and others' behavior (4 items)

Shill and Lumley (2002) conducted a research on the sample of 397 students of psychology, aiming to replicate the original factor structure on a community sample. By extracting five factors, loaded by 21 items, they explained $30 \%$ of the variance. The labels of the factors were kept the same, but they appeared in a different order:

I. Belief in benefits of discussing one's problems (7 items)

II. Access to feelings (4 items)

III. Willingness to discuss problems with others (3 items)
IV. Interest in meaning and motivation of own and others' behavior (3 items)

V. Openness to change (4 items)

In order to test convergent validity, these authors found significant negative correlation between PMS and alexithymia, measured by TAS-20 (Bagby, Taylor, Parker, 1994).

\section{METHODS}

\section{Purpose of the study}

The purpose of this study was to evaluate reliability and validity of the Serbian version of PMS.

\section{Sample}

Our sample consisted of 166 undergraduate students of psychology from the Faculty of Philosophy in Niš. There were 145 female and 21 male participants. The average age was 21, ranging from 19 to 30.

\section{Instruments}

PMS-S (Psychological Mindedness Scale - Serbian version) consists of 45 items. Items are ranged on fourpoint Likert scale from 1 - strongly disagree to $4-$ strongly agree.

TAS-20 (Toronto Alexithymia Scale) consists of 20 items ranged on a five-point Likert scale from 1 - absolutely incorrect to 5 - absolutely correct. The scale comprises the three factors "difficulty identifying feelings", "difficulty describing feelings" and "externally oriented thinking". In this study TAS-20 was used as a measure for the convergent validity of PMS.

\section{Procedure}

The translation process of PMS included the following: three independent translators translated the scale from English to Serbian; the final version was agreed upon after the discussion; back-translation followed by a professional translator who hasn't seen the scale previously; by comparing this with the original version we concluded that the scale was translated adequately. 


\section{RESULTS}

\section{Reliability}

Cronbach's alpha of the PMS-S on our sample was $\alpha=.83$, indicating good internal consistency. The TAS-20 (Bagby et al., 1994) also showed good internal consistency, Cronbach's alpha was $(\alpha=.84)$.

\section{Factor structure}

Following previous studies (Conte et al., 1996; Shill \& Lumley, 2002; Takagishi et al. 2014), we used Principal component analysis with varimax rotation for factor extraction. This resulted in a 15 -factor solution explaining $65.1 \%$ of variance. After considering the scree-plot and cross-loadings we conducted another PCA with a forced 4-factor solution.

Table 1. 4-factor-solution of Serbian PMS after PCA with varimax-rotation.

\begin{tabular}{cccccc}
\hline Factor & Eigenvalue & Explained variance & Number of loading items $(\geq 0.4)$ & Item numbers & Cronbachs $\alpha$ \\
\hline 1 & 4.8 & $10.7 \%$ & 11 & $34,28,4,31,12,16$, & .79 \\
2 & 3.36 & $7.5 \%$ & 7 & $10,22,37,1,35$ & \\
& & & & $23,5,39,43$, & .64 \\
3 & 3.24 & $7.2 \%$ & 8 & $29,33,2,15,26,8$, & .66 \\
4 & 2.95 & $6.6 \%$ & 6 & 40,32 & .71 \\
\hline
\end{tabular}

The four factors with 32 items with factor loadings greater than 0.4 are presented in Table 1. All together the four factors explain $32 \%$ of the variance. We labelled the factors according to the previous nomenclature and the content of the items: the first factor was labelled "Belief in the benefits of discussing one's problems", the second factor "Access to feelings", the third "Interest in meaning and motivation of own and others' behaviour" and the fourth "Openness to new ideas (and capacity for change)" For the sake of easier comparison of factor structures from the previous studies with our results Table 2 shows the excluded factors, number of items which load the factors and the percentage of explained variance. We see that factors Belief in the benefits of discussing one's problems and Interest in meaning and motivation of own and others' behavior in our study contain all of the items which load these factors in other two studies (the only exception is the item 9, which loads the factor Interest in meaning and motivation of own and others' behaviour in the first study). There is a high level of overlap in the case of the factor Openness. We may conclude that these three factors are conceptually similar in all three studies. In case of the factor Access, we can notice that this factor in our study represents the combination of two separate factors from the previous studies - Access and Willingness. This distribution of items is logical, since we chose a fourfactor solution in our study instead of five-factor solutions from the other two studies.

Table 2. Comparison of Factors composition of PMS in Three studies

\begin{tabular}{|c|c|c|c|c|}
\hline & $\begin{array}{c}\text { Name and № of factor } \\
\text { in studies }\end{array}$ & $\begin{array}{l}\text { Explained } \\
\text { variance }\end{array}$ & $\begin{array}{l}\text { Number of } \\
\text { items }\end{array}$ & Items \\
\hline $\begin{array}{l}1 \\
2 \\
3\end{array}$ & $\begin{array}{l}\text { Willingness } 1 \\
\text { Willingness (3) } \\
\text { Willingness }\end{array}$ & $\begin{array}{c}\text { n.r } \\
5.3 \%\end{array}$ & $\begin{array}{c}10 \\
3\end{array}$ & $\begin{array}{c}7,10,13,25,37,38,39,41,42 \\
43 \\
25,37,41\end{array}$ \\
\hline $\begin{array}{l}1 \\
2 \\
3\end{array}$ & $\begin{array}{l}\text { Openness } 2 \\
\text { Openness (5) } \\
\text { Openness (4) }\end{array}$ & $\begin{array}{l}\text { n.r } \\
4.8 \% \\
6.6 \%\end{array}$ & $\begin{array}{l}5 \\
4 \\
6\end{array}$ & $\begin{array}{c}12,26,27,30,31 \\
6,24,27,30 \\
36,6,27,14,24,30\end{array}$ \\
\hline $\begin{array}{l}1 \\
2 \\
3\end{array}$ & $\begin{array}{l}\text { Access } 3 \\
\text { Access }(2) \\
\text { Access }(2)\end{array}$ & $\begin{array}{l}\text { n.r } \\
5.7 \% \\
7.5 \%\end{array}$ & $\begin{array}{l}5 \\
4 \\
7\end{array}$ & $\begin{array}{c}5,11,17,23,35 \\
5,11,23,35 \\
23,5,39,43,17,38,41\end{array}$ \\
\hline $\begin{array}{l}1 \\
2 \\
3\end{array}$ & $\begin{array}{l}\text { Benefits } 4 \\
\text { Benefits (1) } \\
\text { Benefits (1) }\end{array}$ & $\begin{array}{l}\text { n.r } \\
9.01 \% \\
10.7 \%\end{array}$ & $\begin{array}{c}3 \\
7 \\
11\end{array}$ & $\begin{array}{c}4,28,34 \\
4,10,16,22,28,34,31 \\
34,28,4,31,12,16,10,22,37, \\
1,35\end{array}$ \\
\hline
\end{tabular}




\begin{tabular}{l|lccc}
\hline & $\begin{array}{c}\text { Name and № of factor } \\
\text { in studies }\end{array}$ & $\begin{array}{c}\text { Explained } \\
\text { variance }\end{array}$ & $\begin{array}{c}\text { Number of } \\
\text { items }\end{array}$ & Items \\
\hline 1 & Interest 5 & n.r. & 4 & $2,8,9,29$ \\
2 & Interest (4) & $5.1 \%$ & 3 & $2,26,32$ \\
3 & Interest (3) & $7.2 \%$ & 8 & $29,33,2,15,26,8,40,32$ \\
\hline 1 & Total & $38 \%$ & & \\
2 & Total & $30 \%$ & & \\
3 & Total & $32 \%$ & & \\
\hline
\end{tabular}

Studies:1 PMS Study Conte et al. (1996); 2 PMS Study Shill \& Lumley (2002); 3 Present PMS study (Srb sample)

\section{Convergent validity}

The total scores of PMS and TAS-20 correlated strongly negatively with $r=-.67, p<.01$. The correlations with the found PMS factors (see below) are presented in table 3. All four factors correlated significantly with TAS-20. Among them, the second PMS factor (Access to feelings) correlated most strongly with the TAS-20.

Table 3. Correlations of PMS and its four subscales with TAS-20.

\begin{tabular}{|c|c|c|c|c|c|}
\hline & PMS total & Belief & Access & Interest & Openness \\
\hline TAS-20 & $-.67 * *$ & $-.49 * *$ & $-.67 * *$ & $-.24 * *$ & $-.36 * *$ \\
\hline
\end{tabular}

\section{DISCUSSION}

The goal of this study was to test the reliability, factor structure and convergent validity of the Serbian version of Psychological Mindedness Scale. The results indicate that PMS-S is a valid instrument for measuring Psychological Mindedness on the Serbian population. The reliability (internal consistency) is good. The factor analysis showed that in our case the four-factor solution is better than the five-factor solution from the two American studies. The results from yet another study conducted in Japan (Takagishi, Uji, Adachi, 2014), which tested the validity of the scale on their sample, point out that this solution for the factor structure is not a problem. These authors also extracted four factors, and reported on high level of similarity in items which are loading the factors in their study and the two American studies. Due to the percentage of explained variance, as well as the number of items which load the factors, we may conclude that the factor structures presented in all of the studies are similar. Good convergent validity was confirmed by a high negative correlation between the whole PMS-S, as well as its factors separately, and the TAS-20.
Since the number of items which load the extracted factors in all the studies presented is relatively small $(27,21,32$, out of 45$)$ the question of shortening the instrument can be raised. A shorter version of this scale would be more suitable in psychotherapeutic context, both in case of deciding which therapeutic modality would be most suitable for the person, and in case of assessment of the therapeutic progress. Filling out of a shorter instrument takes less time, doesn't influence the contact between the client and the therapist, and takes less effort for the usually disturbed person who just decided to start with psychotherapy. Future research which aims to develop the PMS could analyze the psychometric characteristics of a shorter version of this scale. 


\section{Appendix}

Psychological Mindedness Scale

1. I would be willing to talk about my personal problems if I thought it might help me or a member of my family.

2. I am always curious about the reasons people behave as they do.

3. I think that most people who are mentally ill have something physically wrong with their brain.

4. When I have a problem, if I talk about it with a friend, I feel a lot better.

5. Often I don't know what I'm feeling.

6. I am willing to change old habits to try a new way of doing things.

7. There are certain problems which I could not discuss outside my immediate family.

8. I often find myself thinking about what made me act in a certain way.

9. Emotional problems can sometimes make you physically sick.

10. When you have problems, talking about them with other people just makes them worse.

11. Usually, if I feel an emotion, I can identify it.

12. If a friend gave me advice about how to do something better, I'd try it out.

13. I am annoyed by someone, whether he is a doctor or not, who wants to know about my personal problems.

14. I find that once I develop a habit, it is hard to change, even if I know there is another way of doing things that might be better.

15. I think that people who are mentally ill often have problems which began in their childhood.

16. Letting off steam by talking to someone about your problems often makes you feel a lot better.

17. People sometimes say that I act as if I'm having a certain emotion (anger, for example) when I am unaware of it.

18. I get annoyed when people give me advice about changing the way I do things.

19. It would not be difficult for me to talk about personal problems with people such as doctors and clergymen.

20. If a good friend of mine suddenly started to insult me, my first reaction might be to try to understand why he was so angry.

21. I think that when a person has crazy thoughts, it is often because he is very anxious and upset.

22. I've never found that talking to other people about my worries helps much.
23. Often, even though I know that I'm having an emotion, I don't know what it is.

24. I like to do things the way I've done them in the past. I don't like to try to change my behavior much.

25. There are some things in my life that I would not discuss with anyone.

26. Understanding the reasons you have deep down for acting in certain ways is important.

27. At work, if someone suggested a different way of doing a job that might be better, I'd give it a try.

28. I've found that when I talk about my problems to someone else, I come up with ways to solve them that I hadn't thought of before.

29. I am sensitive to the changes in my own feelings.

30. When I learn a new way of doing something, I like to try it out to see if it would work better than what I had been doing before.

31. It is important to be open and honest when you talk about your troubles with someone you trust.

32. I really enjoy trying to figure other people out.

33. I think that most people with mental problems have probably received some kind of injury to their head.

34. Talking about your worries to another person helps you to understand problems better.

35. I'm usually in touch with my feelings.

36. I like to try new things, even if it involves taking risks.

37. It would be very difficult for me to discuss upsetting or embarrassing aspects of my personal life with people, even if I trust them.

38. If I suddenly lost my temper with someone, without knowing exactly why, my first impulse would be to forget about it.

39. I think that what a person's environment (family, etc.) is like has little to do with whether he develops mental problems.

40. When you have troubles, talking about them to someone else just makes you more confused.

41. I frequently don't want to delve too deeply into what I'm feeling.

42. I don't like doing things if there is a chance that they won't work out.

43. I think that no matter how hard you try, you'll never really understand what makes people tick.

44. I think that what goes on deep down in a person's mind is important in determining whether he will have a mental illness.

45. Fear of embarrassment or failure doesn't stop me from trying something new. 


\section{REFERENCES}

Appelbaum, S. A. (1973). "Psychological-mindedness: word, concept and essence". The International journal of psychoanalysis 54(1), 35-46.

Bagby, R. M., Taylor, G. J., \& Parker, J. D. A. (1994). The twenty-item Toronto Alexithymia Scale: II. Convergent, discriminant, and concurrent validity. Journal of Psychosomatic Research, 38(1), 33-40.

Boylan, M. B. (2006). Psychological Mindedness as a Predictor of Treatment Outcome with Depressed Adolescents. Doctoral dissertation, University of Pittsburgh. http://d-scholarship.pitt. edu/6812/

Conte, H.R., Ratto, R., \& Karusa, T. (1996).The Psychological Mindedness Scale: Factor Structure and relationship to outcome of psychotherapy. Journal of Psychotherapy Practice and Research. 5(3), 250-259

Giromini, L., Brusadelli, E., Di Noto, B., Grasso, R \& Lang, M., (2015). Measuring psychological mindedness: validity, reliability, and relationship with psychopathology of an Italian version of the Balanced Index of Psychological Mindedness. Psychoanalytic Psychotherapy, 29(1), 70-87.

Grant, A. M. (2001). Rethinking psychological mindedness: Metacognition, self-reflection, and insight. Behaviour Change, 18(01), 8-17.

Hall, J. A. (1992). Psychological-mindedness: A conceptual model. American Journal of Psychotherapy, 66(1), 131-140.

Hancheva, C. (2018). "Know thyself" - Psychological mindedness and/or mentalization. Psychology in and around us, 163-174

Krupp, J., Taubner, S., Huber, D., \& Hamburger, A. (2019). Validierung der deutschen Übersetzung der Psychological Mindedness Scale (PMS). Zeitschrift für Psychosomatische Medizin und Psychotherapie, 65(1), 27-41.

McCallum, M., \& Piper, W. E. (1990). The psychological mindedness assessment procedure. Psychological Assessment, 2, 412-418.

Nyklicek, I., \& Denollet, J. (2009). Development and evaluation of the Balanced Index of Psychological Mindedness (BIPM). Psychological Assessment, 21, 32-44

Shill, M.A., \& Lumley, M.A. (2002). The Psychological Mindedness Scale: Factor Structure, Convergent Validity and Gender in a Non-Psychiatric Sample. Psychology and Psychotherapy: Theory, Research and Practice, 75, 131-150.

Takagishi, Y., Uji, M., \& Adachi, K. (2014). Examining the factor structure of the Psychological Mindedness Scale in the Japanese population through exploratory and confirmatory factor analyses. Japanese Psychological Research, 56, 201-209. 